\title{
Effect of a Direct-Fed Microbial on Reproductive Performance in Late Lay Turkey Breeder Hens
}

\author{
Krista N Eberle-Krish, Kenneth E Anderson and Jesse L Grimes* \\ Prestage Department of Poultry Science, North Carolina State University, Raleigh, North Carolina, USA
}

*Corresponding author: Jesse L Grimes, Prestage Department of Poultry Science, North Carolina State University, Scott Hall, 2711 Founders Drive, Raleigh, North Carolina, 27695, USA, Tel: (919) 515-5406; E-mail: jgrimes@ncsu.edu

Received: 26 Sep, 2018 | Accepted: 15 Oct, 2018 | Published: 22 Oct, 2018

Citation: Eberle-Krish KN, Anderson KE, Grimes JL (2018) Effect of a Direct-Fed Microbial on Reproductive Performance in Late Lay Turkey Breeder Hens. J Anim Sci Res 3(1): doi dx.doi.org/10.16966/2576-6457.121

Copyright: (C) 2018 Eberle-Krish KN, et al. This is an open-access article distributed under the terms of the Creative Commons Attribution License, which permits unrestricted use, distribution, and reproduction in any medium, provided the original author and source are credited.

Primary Audience: Turkey breeder flock supervisors; Nutritionists; Poultry researchers

\begin{abstract}
When depopulation is required to end bird suffering and prevent disease transmission, turkey producers must find ways to replace flocks lost. Current production practices are being investigated to prolong the production cycle of turkey breeders. The use of direct fed microbials in poultry diets has demonstrated improvements in immune health, increases in egg quality parameters, and improvement in feed conversion. The overall objective of this research was to evaluate the effect of a direct-fed microbial (PrimaLac ${ }^{\odot}$ ) on reproductive performance in late-lay turkey breeder hens. Large White turkey breeder hens $(n=288)$ were randomly assigned to receive either control or PrimaLac ${ }^{\odot}$ diets for 15 weeks. Eggs were collected twice daily. Total and hen-day egg production was calculated. Eggs were monitored for components (whole egg, yolk, albumen, shell weight) and quality (shell thickness and strength, vitelline membrane strength and deformation) as well as fertility at 54,58 , and 62 weeks of age. Feed consumption, body weight gain, feed conversion, and feed efficiency were determined. A randomized complete block design was used with 4 blocks of 12 pens ( 6 hens/pen). Differences among feed conversion, egg quality and components, and fertility were examined using a linear mixed model. Treatment and sampling period means were separated using least square means. Mean hen-day egg production was at $32.8 \%$ for control and $29.5 \%$ for PrimaLac ${ }^{\odot}$ at 65 weeks. No significant difference was found between treatments for egg quality and component measurements as well as fertility; differences were demonstrated between sampling periods. Feed consumption, body weight gain, feed conversion, and feed efficiency were not significantly different. The PrimaLac ${ }^{\odot}$ hens consumed average of $1.2 \mathrm{~kg}$ less per bird than control hens. While the addition of PrimaLac ${ }^{\odot}$ demonstrated no significant effect on reproductive performance, the study establishes that egg production and fertility can persist in non-molted, single-cycle turkey breeder hens through 65 weeks of age.
\end{abstract}

Keywords: Turkey breeder hen; Egg production; Direct-fed microbial; Egg quality; Fertility; Foreign animal disease outbreak

\section{Introduction}

A notifiable foreign animal disease (FAD) outbreak can cause major economic losses to the food animal industry and disruption to supply for both domestic consumers and international trading partners. The poultry industry experienced this with an outbreak of highly pathogenic avian influenza (HPAI) in 2015 that led to the destruction of over 7 million commercial and breeder turkeys and economic losses over $\$ 3.3$ billion [1,2]. When depopulation is required to end the suffering of birds and prevent further disease transmission, poultry producers must find ways to replace flocks lost. For the turkey industry, it could take months to years to replenish breeding flocks and restock commercial turkey farms. Current production practices are being investigated to see if there are ways to prolong the production cycle of turkey breeder hens if a FAD outbreak leads to the depopulation of large numbers of breeder flocks and/or commercial turkeys.
The addition of probiotics to poultry diets has been explored as a method to improve immune health [3], increase egg quality parameters [4], improve feed conversion [5,6], and reduce pathogen colonization and shedding [7]. Probiotics, also called direct-fed microbials (DFM), are defined as a live microbial feed supplement which beneficially affects the host by improving its intestinal microbial balance [8]. Direct fed microbials are relatively inexpensive and can be easily added to both feed and water at anytime in the production cycle. Russell and Grimes investigated the effect of a dietary DFM on the performance of commercial turkeys [6]. The addition of a DFM resulted in improved mean body weight (BW) and feed conversion ratio (FCR) in female and male turkeys reared to 18 and 20 weeks, respectively [6]. In addition, in two field trials, water delivered DFM resulted in a nominal improvement in bird livability, mean BW, total farm weight of birds, and FCR while cost of production was decreased $(\$ 0.0195 / \mathrm{kg})$. Davis and Anderson also reported significant 
improvements in egg size with lower feed costs in 2 strains of egglaying hens fed dietary DFM compared to hens fed control diets [4]. The DFM influenced a shift from smaller to larger eggs. Grimes et al. also utilized a DFM in laying hens to improve egg production [9]. They observed a shift from smaller to larger eggs and an improved FCR in young and old hens as a result of feeding hens diets supplemented with a DFM [9]. While researchers have investigated the impact of DFM on early and mid-lay turkey breeder hen performance $[10,11]$, no one has examined the influence of a DFM in late-lay turkey breeder hens. The overall objectives of this research were to evaluate the effect of a DFM $\left(\right.$ PrimaLac $\left.{ }^{\odot}\right)$ on egg production, egg quality, feed consumption, and fertility in late-lay turkey breeder hens.

\section{Materials and Methods}

\section{Experimental housing}

All procedures were approved by the North Carolina State University Animal Care and Use Committee. Three hundred Nicholas Large White turkey breeder hens [12] were randomly selected from a commercial turkey flock that had just completed their first egg production cycle. Six hens were placed per pen in 48 pens of a curtain-sided house $(n=288)$ where they were maintained from 50 weeks of age (WOA) to 65 WOA. Each pen was $64 \mathrm{ft}^{2}$ and provided the minimum density required [13]. Fifteen hours of light per day were provided during the study [14]. Two treatments control (C) and $\operatorname{PrimaLac}^{\oplus}(\mathrm{P})$ were randomly assigned to each pen of birds. Hens in $\mathrm{C}$ were fed a typical turkey breeder diet [15] while hens in $\mathrm{P}$ were fed a typical turkey breeder diet containing $1.36 \mathrm{~kg}$ per ton of PrimaLac ${ }^{\circ}$ as prescribed by the product label [16]. Primalac ${ }^{\oplus}$ is supplied as a dry pre-mix containing Lactobacillus acidophilus, Lactobacillus casei, Bifideobacterium thermophilum, and Streptococcus faecium $\left(10^{8}\right.$ cfu/g) [16]. Feed was provided ad libitum from one feeder and one bell drinker per pen. To prevent cross contamination of the microbial agents from $\mathrm{P}$ pens to $\mathrm{C}$ pens, a $321 / 2$ in tall polypropylene barrier was placed between each pen. All daily maintenance activities and egg collection occurred first in $\mathrm{C}$ pens followed by $\mathrm{P}$ pens. Hallways were then washed with water and disinfected with a chlorine bleach solution $(7.5 \%)$ [17].

\section{Feed monitoring}

Individual hen weights were taken upon the beginning and end of the 15-week study. Feed was provided by the North Carolina State Feed Mill. Feed samples were sent immediately upon batching to an external lab for analysis to ensure the correct dosage of PrimaLac $^{\oplus}$ in the $\mathrm{P}$ diet and absence in the $\mathrm{C}$ diet. Each pen of birds was provided $40 \mathrm{lbs}$ feed at placement. The amount of feed was documented when added and feed weigh backs were conducted when mortality was discovered. Feed conversions for body weight gain (BWG) and feed efficiency (expressed as kg feed per kg egg) were calculated.

\section{Egg collection}

Eggs were collected and recorded twice daily to calculate total egg production and percent hen-day production. Eggs used for component, quality and fertility analysis were labeled by pen number and treatment at 54,58 , and $62 \mathrm{WOA}$. All measurements were conducted on 6 eggs per pen, as available. Prior to analysis, all cracked eggs were discarded.

\section{Egg components and quality}

Eggs were monitored for whole egg, yolk, albumen, and shell weight and shell thickness as well as shell strength, vitelline membrane strength, and vitelline membrane deformation at rupture. Eggs used for egg component measurements were placed into a $55^{\circ} \mathrm{F}\left(12^{\circ} \mathrm{C}\right)$ cooler overnight. Weights were monitored with the aid of a computerized electronic measurement device. Shell weight was measured after rinsing shells and drying for $48 \mathrm{hr}$. Shell membranes were included in shell weight. Shell thickness was recorded with a shell thickness gauge [18] at two separate locations around the equator.

Eggs for egg quality monitoring were used the day of collection. Shell strength was recorded according to Jones and Musgrove [19]. Briefly, shell strength was determined with a TA. HDplus Texture Analyzer [20] and Texture Expert Software [20]. Eggs were oriented horizontally on an egg holder [21] so that the 1.5 in diameter acrylic compression disc [22] contacted the equator of the egg. A $50 \mathrm{~kg}$ load cell, $2 \mathrm{~mm} / \mathrm{s}$ test speed, and trigger force of $0.001 \mathrm{~kg}$ were used. Maximum force was recorded as grams of force. Vitelline membrane strength and deformation were recorded according to Jones, et al. [23]. Eggs were individually broken into a shallow dish, allowing orientation of the yolk for penetration along the equatorial region and preventing contact with the germinal disc and chalazae. A $1 \mathrm{~mm}$ rounded end, stainless steel probe [20] was used with a TA. XTplus Texture Analyzer [20] and Texture Expert Software [20] to apply direct pressure to the vitelline membrane until it ruptured. A $500 \mathrm{~g}$ load cell and test speed of $3.2 \mathrm{~mm} / \mathrm{s}$ was utilized. Vitelline membrane strength was measured in grams of force and deformation in $\mathrm{mm}$.

\section{Fertility}

Turkey breeder hens were artificially inseminated weekly using freshly collected and prepared semen from a local turkey breeder male farm. If oviduct eversion did not occur, the hen was marked and checked the next week. If eversion did not occur two weeks in a row, the hen was removed from the flock. Fertility was measured using a sperm: perivitelline layer interaction system [24]. Eggs used for inner perivitelline layer (IPVL) sperm penetration analysis were stored in a $55^{\circ} \mathrm{F}\left(12^{\circ} \mathrm{C}\right)$ walk-in cooler for 24 hours post-lay. The number of IPVL-holes was counted using the IPVL sperm hole assay described by Fairchild et al. [25] and Bakst et al. [26]. Briefly, eggs were cracked open and the yolk was collected while removing all excess albumen. The yolk was placed in a pan with the germinal disc facing up and blotted dry with a Kimwipe [27] to remove any remaining albumen. A $2 \% \mathrm{NaCl}$ solution was poured over the yolk prior to placing a filter ring over the germinal disc (GD), with the GD being in the center of the ring. Scissors were used to cut around the outside of the filter ring. Using forceps, the filter ring and IPL were lifted and flushed with a gentle stream of phosphate buffered saline (PBS) [28] to remove any adherent yolk. The filter ring and IPL were placed on a glass slide and fixed by pipetting 3-4 drops of 3\% formaldehyde over the IPL. After 5 $\mathrm{s}$, the formaldehyde was poured off and 2-3 drops of Schiffs reagent [29] was added. Once the IPL developed a magenta coloration, the excess reagent was poured off and the slide laid out to air dry overnight before microscopic examination at 40x. The GD was centered in the field of view and all holes in the field were counted [30].

\section{Statistical analysis}

A randomized complete block design was used with 4 blocks of 12 pens each. Differences among feed conversion, egg quality and components, and fertility were examined using linear mixed model generated using SAS software [31]. Due to the large differences from egg to egg within a treatment, all IPVL sperm penetration data was transformed by taking the log of holes +1 . Treatment and sampling period means were separated using least square means. Statements of significance are based on $P \leq 0.10$ unless otherwise indicated. 


\section{Results}

The total number eggs produced are presented in Figure 1. At placement, the hens were at $49 \%$ production, which is lower than the expected $56.5 \%$ for hens at 20 weeks of lay [14]. Weekly percent hen-day production is presented in Figure 2. Hen-day egg production declined to $24 \%$ the week of placement most likely due to the stress of movement from the breeder farm to the research facility. Production quickly recovered to around $40 \%$ by $53 \mathrm{WOA}$ and maintained through 60 WOA. Egg production was at $32.8 \%$ and $29.5 \%$ mean hen-day production at the end of the study for $\mathrm{C}$ and $\mathrm{P}$, respectively.

Feed consumption $(P<0.25)$, body weight gain $(P<0.74)$, feed conversion for BWG $(P<0.37)$, and feed efficiency $(P<0.85)$ were not significantly different between treatments (Table 1). The $P$ hens consumed average of $1.2 \mathrm{~kg}$ less per bird than $\mathrm{C}$ hens.

Egg shells collected at 54 WOA were disposed of before shell thickness could be recorded, therefore, no data available for statistical comparison between 54 and 58 WOA. No significant differences were found between treatments for whole egg $(P<0.54)$, yolk $(P<0.46)$, albumen $(P<0.39)$, and shell weight $(P<0.74)$ as well as shell thickness $(P<0.56)$ as observed in table 2 . Whole egg weights did increase over the sampling periods by $0.99 \mathrm{~g}$ and $0.83 \mathrm{~g}$ for $\mathrm{C}$ and $\mathrm{P}$, respectively. There were significant differences between the three sampling periods for yolk $(P<0.0001)$, albumen $(P<0.0001)$, and shell weights $(P<0.0101)$. Yolk weights were significantly higher $(P<0.0001)$ at 58 and $62 \mathrm{WOA}$ when compared to $54 \mathrm{WOA}$ while albumen weights were significantly lower $(P<0.0001)$ at 58 and 62 WOA. Shell weights from $P$ hens were significantly lower $(P<0.0001)$ at $62 \mathrm{WOA}$ than at 54 and 58 WOA. No significant difference was found for vitelline membrane strength $(P<0.64)$ and deformation at rupture $(P<0.19)$ as well as shell

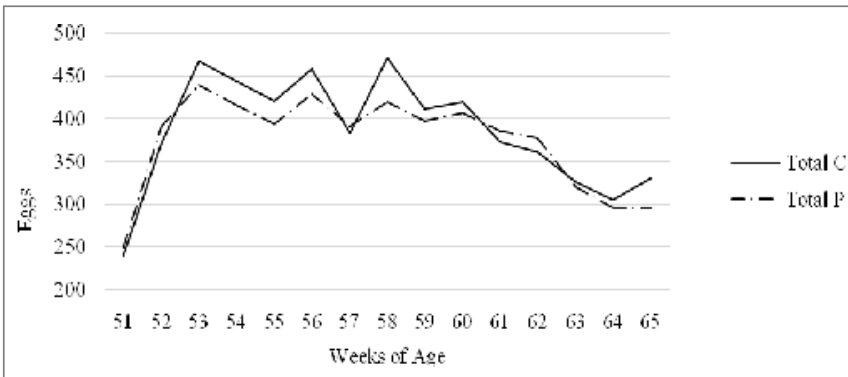

Figure 1: The total weekly egg production for Nicholas Large White turkey breeder hens given a control (C) diet or PrimaLac ${ }^{\odot}(P)$ diet from 51 to 65 weeks of age.

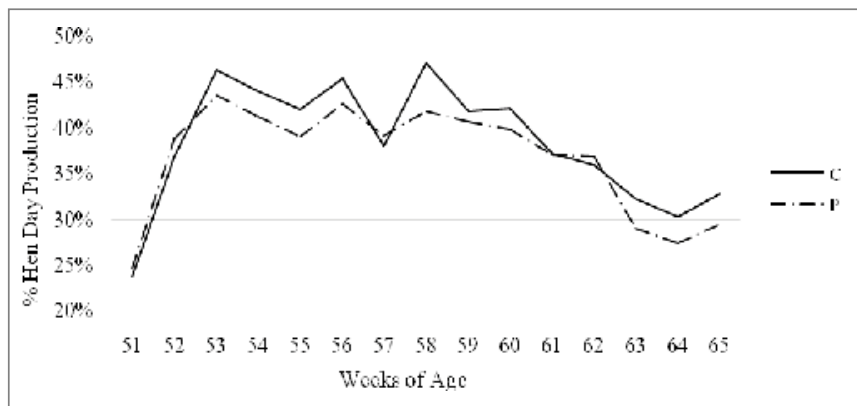

Figure 2: Mean hen-day egg production for Nicholas Large White turkey breeder hens given a control $(\mathrm{C})$ diet or $\operatorname{PrimaLac}^{\odot}(\mathrm{P})$ diet from 51 to 65 weeks of age ( $P$-value $=0.4912 ; \mathrm{SE}=\mathrm{C}: 1.72 \%, \mathrm{P}: 1.56 \%)$. strength $(P<0.94)$ for the two different treatments (Table 3$)$. Like the compositional measurements, there was a significant difference $(P<0.0001)$ between sampling periods for all three measurements. All measurements were significantly higher $(P<0.0001)$ for 54 WOA than 58 and 62 WOA.

No significant difference was found between treatments for IPVLhole counts $(P<0.26)$ and the log of IPVL-hole counts $(P<0.27)$ however, there were differences found between sampling periods. For both $\mathrm{C}$ and $\mathrm{P}$ eggs collected at 54 and 58 WOA had significantly higher counts of IPVL-holes (C: $P<0.01 ; \mathrm{P}: P<0.02)$ and log of IPVL-holes (C: $P<0.01$; $P$ : $P<0.002)$ than eggs at 62 WOA (Table 4 ). It was observed that only one hen throughout the 15 weeks study was removed due to the lack of oviduct eversion.

\section{Discussion and Conclusion}

It is understood that hen age and diet influences egg characteristics and fertility; however little work has been reported to demonstrate turkey breeder hen reproductive performance after 54 WOA. A significant increase in yolk weight and decrease in albumen and shell weight observed in this study is consistent with previous reports $[32,33]$.

Sperm penetration of the IPVL, first performed by Bramwell and Howarth has been found to positively correlate with fertility [34,35]. Although the IPVL-hole counts decreased significantly by the end of the study, they were still higher than the counts demonstrated by Fairchild and Christensen [36]. The investigators found log transformed mean IPVL-hole counts of 1.40 for young hens ( $32 \mathrm{WOA}$ ) and 0.77 for old hens (44 WOA). In the current study, log transformed mean IPVLhole counts of 1.73 for $\mathrm{C}$ and 1.60 for P at 65 WOA were observed. Other factors that have been found to affect sperm penetration include tom age [37], insemination dose [36], and the insemination frequency [38]. Future research on fertility in late-lay breeder hens should include assessing these factors.

While the addition of DFM to the hen's diet demonstrated no significant effect on hen-day egg production, egg quality, feed consumption, or fertility, the current study establishes that egg production and fertility can persist in non-molted, single-cycle turkey breeder hens through 65 WOA. Cleaver et al. stated that their control treatment ceased egg production before 64 WOA when their molted treatment came into its second cycle of production [39]. Atkinson et al. also demonstrated persistence of egg production in late-lay breeder hens using light restriction and induced molting [40]. A late-lay breeder flock was separated it into 3 groups molt with light restriction, molt with no light restriction, and light restriction and provided an 8 weeks treatment period prior to starting a second lay cycle. The light restriction group was able to maintain $45 \%$ production during the second cycle compared to $47 \%$ and $38 \%$ production for the molt with light restriction and molt with no light restriction, respectively. The researchers suggested it may not be necessary to induce molt to achieve a successful second production cycle.

Induced molting is another practice that could be further explored to extend egg production in turkey breeder hens. Molting is a natural physiological process where a bird sheds and replaces feathers as well as experiences a reproductive "resting period" where the reproductive tract regresses and little to no eggs are produced [41,42]. Cleaver et al. determined that an 8-week light restricted and short-term feed and water restricted molting program could revive a breeder flock's mean hen-day egg production to over $50 \%$ for another 20 weeks [39]. One difference future research would need to account for is that feed and water restriction are no socially longer acceptable to induce 
Table 1: Egg production, body weight, and mean cumulative FCR for Nicholas large white turkey breeder hens with or without a dietary direct-fed microbial (PrimaLac ${ }^{\circledR 1}$ ).

\begin{tabular}{|c|c|c|c|c|c|c|c|}
\hline & Total Eggs & Avg Eggs/Hen & $\begin{array}{c}\text { Total Egg Mass/Hen } \\
\text { (kg/bird) }\end{array}$ & $\begin{array}{c}\text { Feed Consumption } \\
\text { (kg/bird) }\end{array}$ & $\begin{array}{l}\text { Body Wt Gain } \\
\text { (kg/bird) }\end{array}$ & $\begin{array}{l}\text { Feed Conversion } \\
\text { for BWG }\end{array}$ & Feed Efficiency ${ }^{2}$ \\
\hline$C^{3}$ & 5781 & $42.14 \pm 1.88$ & $4.09 \pm 0.18$ & $36.03 \pm 0.71$ & $0.27 \pm 0.07$ & $2.74 \pm 0.05$ & $9.19 \pm 0.43$ \\
\hline $\mathrm{P}$ & 5610 & $40.33 \pm 1.37$ & $3.95 \pm 0.13$ & $34.82 \pm 0.76$ & $0.24 \pm 0.08$ & $2.65 \pm 0.05$ & $9.08 \pm 0.39$ \\
\hline
\end{tabular}

${ }^{1}$ PrimaLac ${ }^{\odot}$ (Star Labs, Inc., Clarksdale, MO) fed at $1.36 \mathrm{~kg} /$ ton

${ }^{2}$ Feed efficiency expressed as kg feed per kg egg

${ }^{3}$ Treatments: control (C) and PrimaLac ${ }^{\odot}(\mathrm{P})$

Table 2: Compositional (whole egg, yolk, albumen, and shell weight) and shell thickness measurements for Nicholas Large White turkey breeder hens with or without a dietary direct-fed microbial (PrimaLac ${ }^{\oplus 1}$ ) at 54, 58, and 62 weeks of age.

\begin{tabular}{|c|c|c|c|c|c|}
\hline Weeks of Age & Whole Egg & Yolk & Albumen & Shell & Shell Thickness \\
\hline$C^{2}$ & (g) & (g) & (g) & (g) & $(\mathrm{mm})$ \\
\hline 54 & $96.44 \pm 0.79^{a}$ & $29.10 \pm 0.31^{a}$ & $63.35 \pm 0.99^{a}$ & $8.33 \pm 0.18^{a}$ & NA \\
\hline 58 & $97.74 \pm 0.81^{\mathrm{a}}$ & $30.21 \pm 0.31^{b}$ & $59.06 \pm 1.03^{b}$ & $8.45 \pm 0.18^{a}$ & $0.41 \pm 0.004^{a}$ \\
\hline 62 & $97.43 \pm 0.94^{\mathrm{a}}$ & $30.67 \pm 0.34^{b}$ & $58.73 \pm 1.21^{b}$ & $8.00 \pm 0.21^{a}$ & $0.40 \pm 0.004^{a}$ \\
\hline $\mathrm{P}$ & (g) & (g) & (g) & (g) & $(\mathrm{mm})$ \\
\hline 54 & $97.20 \pm 0.82^{\mathrm{a}}$ & $28.83 \pm 0.32^{\mathrm{a}}$ & $64.56 \pm 1.03^{a}$ & $8.82 \pm 0.19^{a}$ & NA \\
\hline 58 & $97.74 \pm 0.84^{\mathrm{a}}$ & $30.03 \pm 0.31^{b}$ & $59.79 \pm 1.05^{b}$ & $8.15 \pm 0.18^{b}$ & $0.40 \pm 0.004^{a}$ \\
\hline 62 & $98.03 \pm 0.97^{a}$ & $30.61 \pm 0.35^{b}$ & $59.40 \pm 1.25^{b}$ & $7.99 \pm 0.22^{b}$ & $0.40 \pm 0.005^{a}$ \\
\hline
\end{tabular}

${ }^{1}$ PrimaLac ${ }^{\odot}$ (Star Labs, Inc., Clarksdale, MO) fed at $1.36 \mathrm{~kg} /$ ton

${ }^{2}$ Treatments: control $(\mathrm{C})$ and PrimaLac $^{\odot}(\mathrm{P})$

${ }^{a, b}$ Means within column within each treatment with no common superscript are significantly different at $P<0.10$

Table 3: Shell strength, vitelline membrane break strength and deformation at rupture, and inner perivitelline layer hole count for Nicholas Large White turkey breeder hens with or without a dietary direct-fed microbial (PrimaLac ${ }^{\circledR 1}$ ) at 54, 58, and 62 weeks of age.

\begin{tabular}{|c|c|c|c|}
\hline $\begin{array}{c}\text { Weeks } \\
\text { of Age }\end{array}$ & Shell strength & $\begin{array}{c}\text { Vitelline } \\
\text { membrane } \\
\text { breaking strength }\end{array}$ & $\begin{array}{c}\text { Vitelline membrane } \\
\text { deformation at } \\
\text { rupture }\end{array}$ \\
\hline$C^{2}$ & (g) & (g) & (mm) \\
\hline 54 & $6922.57 \pm 208.51^{\mathrm{a}}$ & $5.32 \pm 0.08^{\mathrm{a}}$ & $6.29 \pm 0.11^{\mathrm{a}}$ \\
\hline 58 & $5360.61 \pm 199.44^{\mathrm{b}}$ & $2.38 \pm 0.08^{\mathrm{b}}$ & $4.13 \pm 0.10^{\mathrm{b}}$ \\
\hline 62 & $4986.38 \pm 263.23^{\mathrm{b}}$ & $2.30 \pm 0.09^{\mathrm{b}}$ & $4.09 \pm 0.12^{\mathrm{b}}$ \\
\hline $\mathrm{P}$ & $\mathbf{( g )}$ & $\mathbf{( g )}$ & $(\mathbf{m m})$ \\
\hline 54 & $6927.01 \pm 205.01^{\mathrm{a}}$ & $5.33 \pm 0.08^{\mathrm{a}}$ & $6.51 \pm 0.09^{\mathrm{a}}$ \\
\hline 58 & $5329.38 \pm 223.85^{\mathrm{b}}$ & $2.39 \pm 0.09^{\mathrm{b}}$ & $4.26 \pm 0.11^{\mathrm{b}}$ \\
\hline 62 & $4928.37 \pm 282.19^{\mathrm{b}}$ & $2.38 \pm 0.11^{\mathrm{b}}$ & $4.20 \pm 0.13^{\mathrm{b}}$ \\
\hline
\end{tabular}

${ }^{1}$ PrimaLac ${ }^{\odot}$ (Star Labs, Inc., Clarksdale, MO) fed at $1.36 \mathrm{~kg} /$ ton

${ }^{2}$ Treatments: control $(\mathrm{C})$ and PrimaLac ${ }^{\odot}(\mathrm{P})$

${ }^{a, b}$ Means within column for each treatment with no common superscript are significantly different at $\mathrm{P}<0.10$

molt. Koelkbeck and Anderson demonstrated in laying hens that postmolt egg production utilizing non-feed withdrawal techniques are comparable to feed and water restriction [43]. Non-feed withdrawal techniques use low protein/energy, high fiber maintenance diets utilizing various feed ingredients such as corn, dried distillers' grain, soybeans hulls, alfalfa, and wheat middlings [44-48] to slow or stop egg production. Before induced molting could be considered an accepted option, research would be needed to determine the effectiveness of non-feed withdrawal techniques in turkey breeder hens.
Table 4: The mean and log transformed mean sperm penetration holes hydrolyzed in the inner perivitelline layer of Nicholas Large White turkey breeder hens with or without a dietary direct-fed microbial (PrimaLac ${ }^{\circledR 1}$ ) at 54,58 , and 62 weeks of age.

\begin{tabular}{|c|c|c|}
\hline Weeks of Age & Mean IPVL-holes $^{3}$ & Log of IPVL-holes \\
\hline$C^{2}$ & & \\
\hline 54 & $29.93 \pm 5.98^{\mathrm{a}}$ & $2.04 \pm 0.09^{\mathrm{a}}$ \\
\hline 58 & $31.07 \pm 4.60^{\mathrm{a}}$ & $2.10 \pm 0.07^{\mathrm{a}}$ \\
\hline 62 & $10.76 \pm 6.29^{\mathrm{b}}$ & $1.73 \pm 0.09^{\mathrm{b}}$ \\
\hline$P$ & & \\
\hline 54 & $35.15 \pm 7.24^{\mathrm{a}}$ & $1.95 \pm 0.12^{\mathrm{a}}$ \\
\hline 58 & $24.85 \pm 4.29^{\mathrm{a}}$ & $2.00 \pm 0.07^{\mathrm{a}}$ \\
\hline 62 & $10.40 \pm 5.49^{\mathrm{b}}$ & $1.60 \pm 0.09^{\mathrm{b}}$ \\
\hline
\end{tabular}

${ }^{1}$ PrimaLac ${ }^{\odot}$ (Star Labs, Inc., Clarksdale, MO) fed at $1.36 \mathrm{~kg} /$ ton ${ }^{2}$ Treatments: control (C) and PrimaLac ${ }^{\odot}$ (P) ${ }^{3} \mid \mathrm{PV} L$-inner perivitelline layer

a,b Means within column for each treatment with no common superscript are significantly different at $\mathrm{P}<0.10$

Another issue with using light restriction or induced molting is that these production practices require an 8-10 week period where hens are not producing eggs. Allowing downtime in egg production might not be feasible in the event of a FAD outbreak if many breeder or commercial replacement flocks needed due to depopulation of infected flocks. Further research is needed not only for light restriction and non-feed withdrawal molting techniques, but for other ways turkey producers can extend egg production without any downtime required. 
Overall, this study demonstrated the ability for late cycle turkey breeder hens to maintain egg production and fertility through $65 \mathrm{WOA}$ without the need for induced molt. This option could be extremely helpful in the event of a FAD when replacement birds are needed due to depopulation of infected flocks.

\section{Acknowledgements}

The authors would like to acknowledge the staff of the Talley Turkey Education Unit at NC State University, including Stephen Hocutt, Brooke Griffith, Michael Mann, Dannica Wall, Jerry Deloatch, Kaitlyn Boykin, Hill Pence, Elizabeth Deese, and Zane Hocutt, for all their assistance with bird management and egg collection. The authors also appreciate the laboratory efforts of Vickie Hedgepath of the Prestage Department of Poultry Science at NC State University.

\section{References}

1. Greene JL (2015) Update on the Highly-Pathogenic Avian Influenza Outbreak of 2014-2015. Congressional Research Service (CRS) Report No R44114.

2. Animal Health and Plant Inspection Service, USDA (2016) HPAI 20142015 Infected Premises.

3. Dalloul RA, Lillehoj HS, Shellem TA, Doerr JA (2003) Enhanced mucosal immunity against Eimeria acervulina in broilers fed a Lactobacillus-based probiotic. Poult Sci 82: 62-66.

4. Davis GS, Anderson KE (2002) The effects of feeding the direct-fed microbial, primalac ${ }^{\circ}$, on growth parameters and egg production in single comb white leghorn hens. Poult Sci 81: 755-759.

5. Nayebpor M, Farhomand P, Hashemi A (2007) Effects of Different Levels of Direct Fed Microbial (Primalac ${ }^{\odot}$ ) on Growth Performance and Humoral Immune Response in Broiler Chickens. J Anim Vet Adv 6: 1308-1313.

6. Russell SM, Grimes JL (2008) The effect of a direct-fed microbial (Primalac ${ }^{\circ}$ ) on turkey live performance. J Appl Poult Res 18: 185192.

7. Grimes IL, Rahimi S, Oviedo E, Sheldon BW, Santos FB (2008) Effects of a direct-fed microbial (primalac ${ }^{\odot}$ ) on turkey poult performance and susceptibility to oral Salmonella challenge. Poult Sci 87: 14641470.

8. Fuller R (1989) Probiotics in man and animals. J Appl Bacteriol 66: 365-378.

9. Grimes JL, Maurice DV, Lightsey SF, Lopez JG (1997) The Effect of Dietary Fermacto on Layer Hen Performance. J Appl Poult Res 6: 399-403.

10. Hayat J, Savage TF, Mirosh LW (1993) The reproductive performance of two genetically distinct lines of medium white turkey hens when fed breeder diets with and without a yeast culture containing Saccharomyces cerevisiae. Anim Feed Sci Tech 43: 291-301.

11. Bradley GL, Savage TF (1995) The influences of pre-incubation storage duration and genotype on the hatchability of Medium White turkey eggs from hens fed a diet containing a yeast culture of Saccharomyces cerevisiae. Anim Feed Sci Tech 51: 141-152.

12. Aviagen Turkeys, Lewisburg, WV, USA.

13. Aviagen Turkeys (2015a) Management Guidelines: Turkey Breeders.

14. Aviagen Turkeys (2015b) Nicholas Select Breeder Information. Reproductive Performance Objectives.

15. Aviagen Turkeys (2010) Nicholas Breeder Feed Recommendations for Parent Stock.

16. PrimaLac ${ }^{\odot} 454$ Feed Grade, Star Labs/Forage Research, Inc., Clarksdale, MO, USA.
17. Clorox Outdoor Bleach, The Clorox Company, Oakland, CA, USA.

18. SpeedMic IP54 Digital Caliper, iGaging, San Clemente, CA, USA.

19. Jones DR, Musgrove MT (2005) Correlation of eggshell strength and Salmonella enteritidis contamination of commercial shell eggs. J Food Prot 68: 2035-2038.

20. Texture Technologies, Corp., Scarsdale, NY, USA.

21. TA-ESR, Texture Technologies, Corp., Scarsdale, NY, USA

22. TA-4, Texture Technologies, Corp., Scarsdale, NY, USA.

23. Jones DR, Tharrington JB, Curtis PA, Anderson KE, Keener KM, et al. (2002) Effects of cryogenic cooling of shell eggs on egg quality. Poult Sci 81: 727-733.

24. Wishart GJ, Staines HJ (1999) Measuring sperm:egg interaction to assess breeding efficiency in chickens and turkeys. Poult Sci 78: 428436.

25. Fairchild BD (2001) Turkey hen age, fertility, and sperm penetration of the inner perivitelline layer affects embryonic mortality. PhD Diss. North Carolina State University, Raleigh, NC, USA.

26. Bakst MR, Eastridge J, Malecki IA (2014) The inner perivitelline layer sperm hole assay: Use of filter paper rings for the isolation of the perivitelline layer overlying the germinal disc and new observations on its morphology. J Appl Poult Res 23: 121-128.

27. Kimberly-Clark Professionals, Neenah, WI, USA.

28. Acumedia, Lansing, MI, USA.

29. Sigma-Aldrich, St. Louis, MO, USA.

30. Donoghue AM (1996) The effect of twenty-four hour in vitro storage on sperm hydrolysis through the perivitelline layer of ovipositioned turkey eggs. Poult Sci 75: 1035-1038.

31. SAS Institute (2014) SAS 9.4 Users Guide, SAS Institute Inc., Cary, NC, USA.

32. RahnH, Christensen VL, Edens FW (1981) Changes in Shell Conductance, Pores, and Physical Dimensions of Egg and Shell During the First Breeding Cycle of Turkey Hens. Poult Sci 60: 25362541.

33. Mroz E, Stephinska M, Krawczyk M (2014) Morphology and chemical composition of turkey eggs. J Appl Poult Res 23: 196-203.

34. Bramwell RK, Howarth B Jr (1992) Preferential attachment of cock spermatozoa to the perivitelline layer directly over the germinal disc of the hen's ovum. Biol Reprod 47: 1113-1117.

35. Wishart GJ (1997) Quantitative aspects of sperm: egg interaction in chickens and turkeys. Anim Reprod Sci 48: 81-92.

36. Fairchild BD, Christensen VL (2005) Influence of Hen Age and Number of Inseminated Sperm on the Number of Holes Hydrolyzed in the Inner Perivitelline Layer of Turkey Eggs. J Appl Poult Res 14: 576-581.

37. Bramwell RK, McDaniel CD, Wilson JL, Howarth B (1996) Age effect of male and female broiler breeders on sperm penetration of the perivitelline layer overlying the germinal disc. Poult Sci 75: 755-762.

38. Christensen VL (1981) Effect of insemination intervals on oviducal sperm storage in turkeys. Poult Sci 60: 2150-2156.

39. Cleaver WT, Christensen VL, Ort JF (1986) Physiological characteristics of a molt and second cycle of egg laying in turkey breeder hens. Poult Sci 65: 2335-2342.

40. Atkinson RL, Bradley JW, Schom CB, Ferguson TM, Krueger WF (1974) Recycling Turkey Hens. Poult Sci 53: 847-849.

41. Heuser GF (1893) Feeding Poultry. John Wiley \& Sons, Inc. $2^{\text {nd }}$ Edition, New York, USA, 398-399. 
42. Rice JE (1909) The Feeding of Poultry. In: Johnson WG, Brown GO (eds) The Poultry Book. Doubleday, New York, USA, 190-192.

43. Koelkebeck KW, Anderson KE (2007) Molting layers--alternative methods and their effectiveness. Poult Sci 86: 1260-1264.

44. Biggs PE, Persia ME, Koelkebeck KW, Parsons CM (2004) Further evaluation of nonfeed removal methods for molting programs. Poult Sci 83: 745-752.

45. Donalson LM, Kim WK, Woodward CL, Herrera P, Kubena LF, et al. (2005) Utilizing different ratios of alfalfa and layer ration for molt induction and performance in commercial laying hens. Poult Sci 84: 362-369.
46. Landers KL, Woodward CL, Li X, Kubena LF, Nisbet DJ, et al. (2005) Alfalfa as a single dietary source for molt induction in laying hens. Bioresour Technol 96: 565-570.

47. Koelkbeck KW, Parsons CM, Biggs P, Utterback P (2006) Non-feed withdrawal molting programs. Poult Sci 15: 483-491.

48. Anderson KE, Havenstein GB (2007) Effects of Alternative Molting Programs and Population on Layer Performance: Results of the Thirty-Fifth North Carolina Layer Performance and Management Test. J Appl Poult Res 16: 365-380. 